\title{
Automation of the Process of Modelling Sales Volume Dynamics of Light Weight Vehicles in the Russian Market, Using Customer Satisfaction as a Yardstick
}

\author{
Aleksey Solntsev ${ }^{1 *}$, Valeliy Zenchenko ${ }^{1}$, Vitaly Guliy ${ }^{1}$, Alexander Chekanov $^{1}$ and Khizar \\ Dzhabrailov ${ }^{1}$ \\ ${ }^{1}$ Moscow Automobile and Road Construction State Technical University (MADI), 64 Leningradsky \\ prosp., Moscow, 125319, Russia
}

\begin{abstract}
This paper takes a look at the questions surrounding the analysis of sales volume forecast of light weight vehicle of selected Makes/Brands in the Russian Market, taking into consideration the rating distribution of customer satisfaction. The link between the changes and fluctuations in the sales of LWV in combination with the cyclical processes of the level of economic activity is being considered.
\end{abstract}

\section{Introduction}

This paper presents the results of intensive studies carried out by the Department of Road Transport Operations, Moscow State Automobile and Road Technical University (MADI), reflecting the identification of sales volume of light weight vehicle (hereinafter as LWV) in the retrospective period, with a subsequent modeling of sales volume forecast of all light weight vehicles introduced into the Russian market, as well as individual sets of selected makes and brands with the highest index of satisfaction level $[1,2]$. In same vein the, the relationship between sales volume, the change in economic situation because of the investment and business cycles, including the sphere of introducing the LWV into the Russian auto market is being taken into consideration.

\section{Material and methods}

From the study of the previous paper, the rationale behind the selection of a cluster of vehicle makes and brands with high index level of customer satisfaction of LWV (from the TOP-30), being introduced into the Russian automotive market, that contains BMW, Land Rover, Lexus, Honda, Mercedes, Toyota, Audi, Volvo (see figure 1). These LWV makes/brands has the highest customer satisfaction index level, the lower control boundary for a given probability of $\gamma=0,95$ equals $U_{\gamma=0,95}^{b r . n}=U_{b r}=84,73$. The differential function, expressing the

* Corresponding author: author@email.org 
distribution ratings of the satisfaction level of the selected LWV makes/brands can be seen in fig. 2. Assessment and constructive functions were based on the known locations of the mathematical apparatus of probability theory and mathematical statistics $[6,9]$.

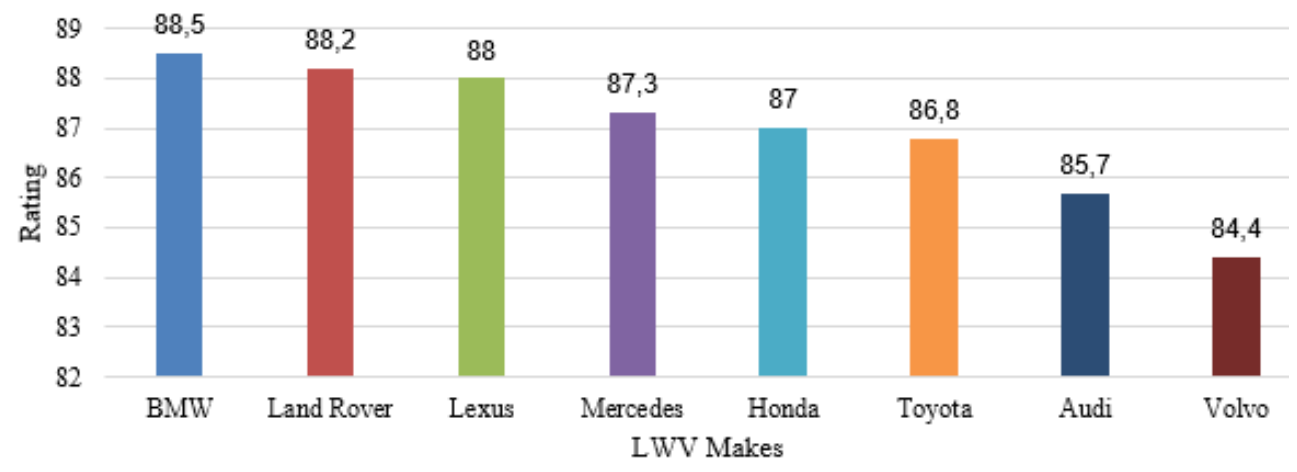

Fig. 1. Satisfaction rating distribution of LWV Makes.

$\mathrm{f}(\mathrm{U})$

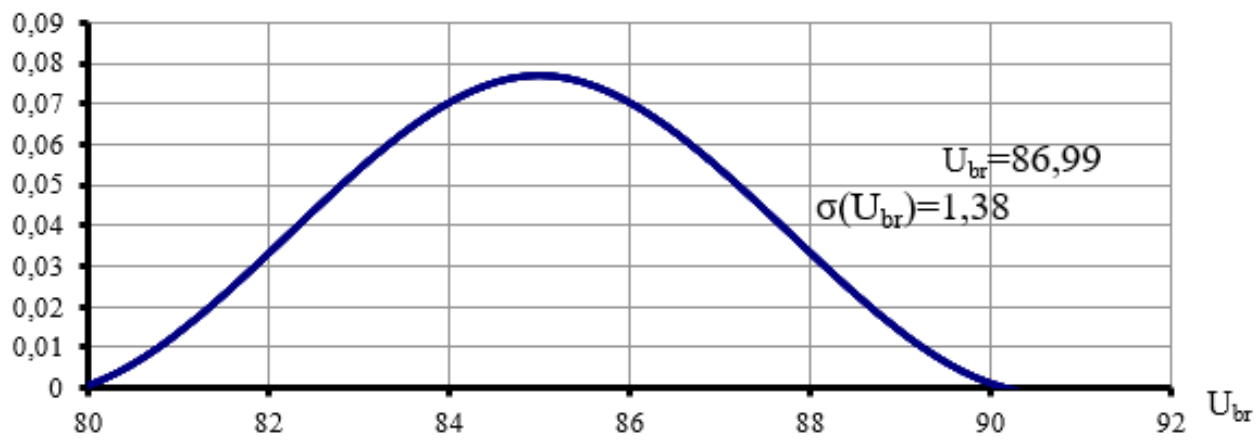

Fig. 2. The differential function of the distribution ratings of customers satisfaction of selected brands/makes of LWV (BMW, Land Rover, Lexus, Honda, Mercedes, Toyota, Audi, Volvo).

In accordance with the presented study plan, based on the statistical information of the «European Business Association (EBA)» (see. figure 1), the forecast model for the change in sales volume dynamics of $\operatorname{LWV}\left(Q_{t}\right)$ for the short and medium term was achieved.

The simulation of $\left(Q_{t}\right)$ on a sufficient period, can be described to be reliable with the nth order regression equation followed by the estimate of the resonance in sales volume, including the identification of the lower and upper control boundaries with a given probability $\gamma[3,4,6-8,10-18]$.

The trend reflecting the change in sales dynamics $Q_{(t)}=f(t)$ can be expressed using the regression equation of the form:

$$
Q_{t}=a_{0}+a_{1} \cdot t+\ldots+a_{i} \cdot t^{i}+\ldots+a_{n} \cdot t^{n},
$$

where $a_{0}, a_{1}, \ldots, a_{i}, \ldots, a_{n}$ - regression coefficients;

$t$ - independent value of the current period of the year, which is calculated as:

$$
t=T-T_{0} \text {. }
$$

In the expression (2) above, $T$ stands for the variables of the current years from 2005 to 2025 , while $T_{0}$ is the year of reference to the origin of the coordinates which is 2004.

The statistical information of the «European Business Association (EBA)» [2], was used as the initial tool for forecasting $Q_{(t)}=f(t)$, see. figure 3 . 


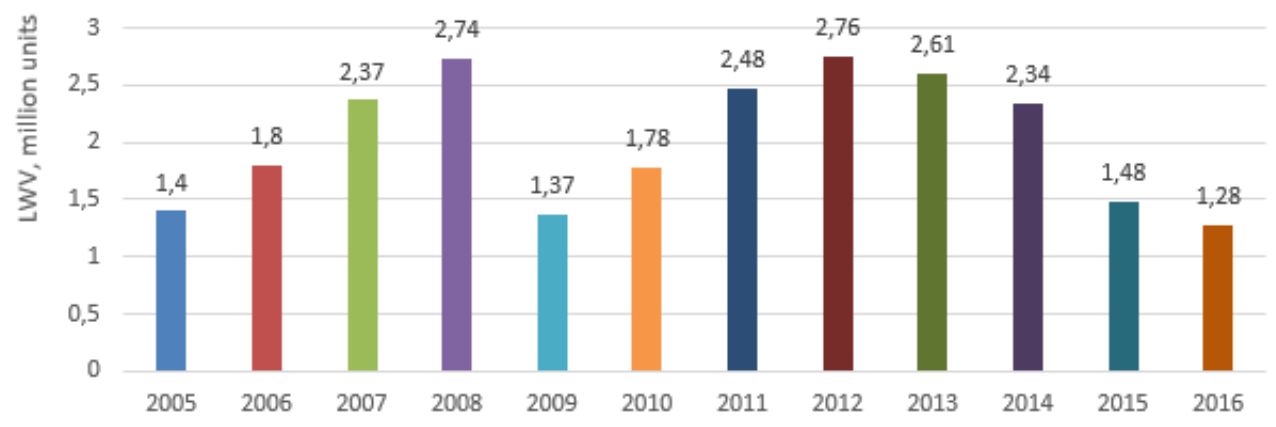

Years

Fig. 3. The Fragment of sales volume dynamics of LWV in the Russian Federation from 2005-2016 (million units).

The results of the highlighted processed information shown in fig. 3 makes it possible to simulate the sales volume $\left(Q_{t}\right)$ within a period from 2005 to 2025 -year (i.e. from $t_{l}=1$ to $\left.t_{n}=21\right)$ and obtain the predictive estimates of the changes in trends as well as the lower and upper true boundaries for a given probability $\gamma=0,9$, that is,

- for the trend:

$$
Q_{t}=0,3921+1,4019 t-0,4329 t^{2}+0,0673 t^{3}-0,0054 t^{4}+0,0002 t^{5}-3 E-06 t^{6}
$$

- for the upper true boundaries:

$$
Q_{t \gamma}^{B}=0,802+1,4019 t-0,4329 t^{2}+0,0673 t^{3}-0,0054 t^{4}+0,0002 t^{5}-3 E-06 t^{6}
$$

- for the lower true boundaries:

$$
Q_{t \gamma}^{H}=0,0178+1,4019 t-0,4329 t^{2}+0,0673 t^{3}-0,0054 t^{4}+0,0002 t^{5}-3 E-06 t^{6}
$$

At same time, a sufficiently high correlation was found between the experimental and theoretical values, whose coefficient equals $r=0,775$.

Fig. 4 shows the graphical representation of the simulation result of the trend $Q_{t}$, its upper $Q_{t \gamma}^{b}$, and lower $Q_{t \gamma}^{n}$ true boundaries for the given probability $\gamma=0.9$.

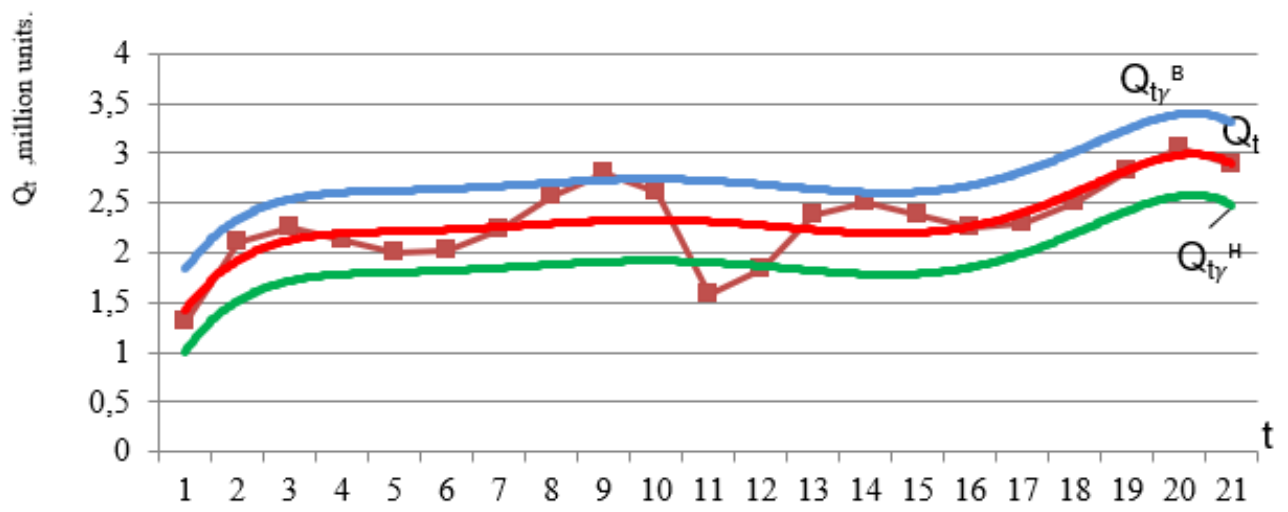

Fig. 4. The sales volume model of $Q_{t}, Q_{t \gamma}^{b}, Q_{t \gamma}^{n}$ within a period of $t=(\overline{1,21,1})$ and $T=(\overline{2004,2025,1})$. 
The wave behavioural pattern of $Q_{t}$ is a function of the change in economic situations in the LWV market, which is determined by investment plan and business cycle functioning of the economy (see figure 3), [5].
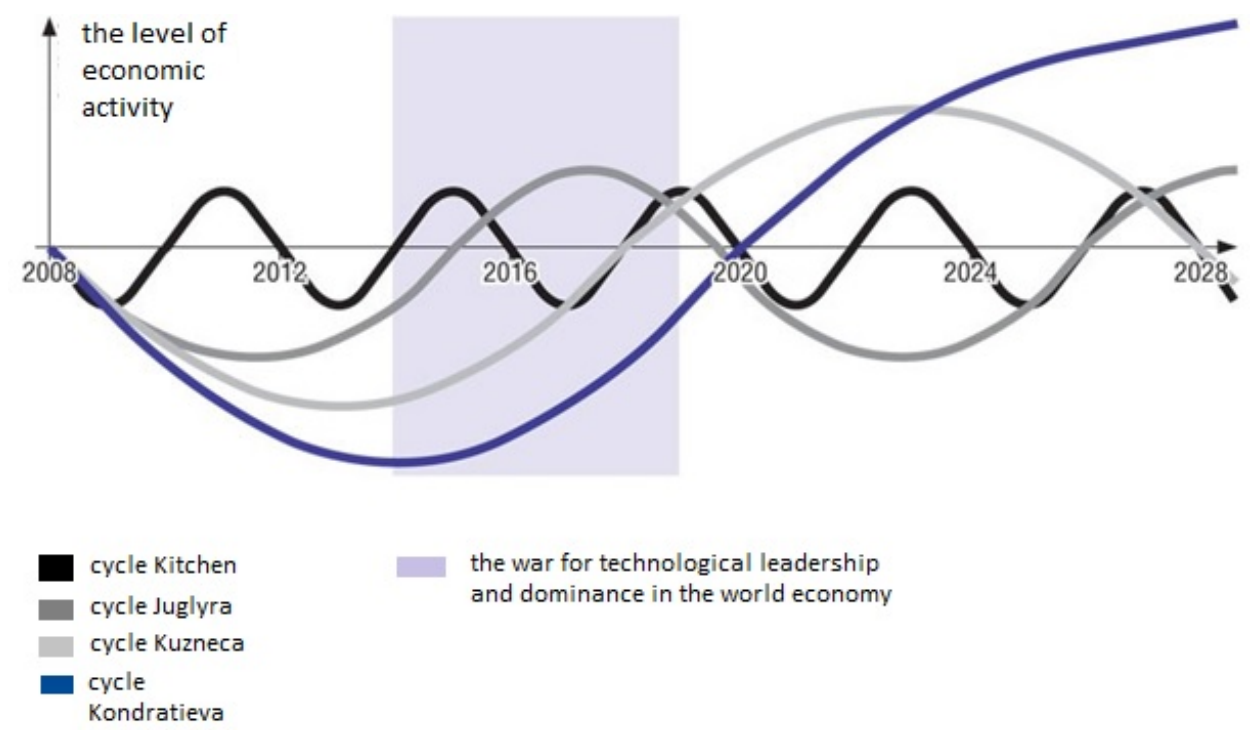

the war for technological leadership

and dominance in the world economy

Fig. 5. The global economic crisis as a combination of cyclical processes.

The analysis of the simulation results of sales volume $Q_{t}$ shown in fig.4 and the level of activities of economical cyclical processes (see figure 5) shows that, from the period of 2005 $\left(t_{1}=11\right)$ to $2025\left(t_{n}=21\right)$, there is a convergence of the forecast results in change of $Q_{t}$ with cycles of Zhigler and Kuznets in the zones of technological advancements and dominance in world economy.

\section{Conclusion}

The obtained results allowed us to reasonably and purposefully approach the questions of forecasting the promotion/introduction of selected brand brands of passenger vehicles to the Russian market with the aim of subsequent justification of the possibility of developing the Inventory Management System (IMS) for spare parts and materials.

\section{References}

1. «AUTOSTAT Analytical Agency» www.autostat.ru., (2016)

2. «European Business Association (EBA)» www.aebrus.ru., (2016)

3. S.V. Arzhenovsky, I.N. Molchanov, Statistical Forecasting Methods. Study Materials / Rostov State Economic University - Rostov-n / D., 74 p. (2001)

4. M.V. Grigoryev, V.A. Zenchenko, The Problems of forecasting the introduction of auto-service services in ensuring the operational capabilities of the elements of transportation-technological complexes. Collection of scientific papers on the materials of the 75th scientific-methodical and scientific-research conference MADI, Technnological Polygraphic center, 267p. (2017) 
5. S.U. Glazyev, On the urgent measures in strengthening Russia's economic security to the trajectory of advanced development. Report / S.U. Glazyev. Moscow: Institute for Economic Strategies, Russian Biographical Institute, 60 p. (2015)

6. R.S. Guter, B.V. Ovchinsky, Elements of numerical analysis and mathematical processing of experimental results. - M., "Science", the main edition of physical and mathematical reference, 432 p. (1970)

7. Y.V. Zavadsky, Solving the problems road transportation and road building machines by means of regression-correlation analysis (Training manual for FPK listeners) - M .: 116 p. (1981)

8. V.A. Zenchenko, D.V. Antonov, Forecasting the Development of the Vehicle Service Market. Methodological Guidelines for Seminars on the "Fundamentals of Marketing in the Vehicle Service Sector". MADI. - Moscow., 48 p. (2011)

9. I.I. Eliseeva, V.S. Knyazevskiy, L.I. Novorozhkina, Z.A.Morozova, Statistical Theory with the Fundamentals of the Theory of Probabilities.: High School Manual. Moscow.: UNITY-Dana, 446 p. (2001)

10. E.S. Kuznetsov, A.P. Boldin, V.M. Vlasov, and others. Technical operation of vehicles: A textbook for high schools. 4 th ed., / E. - Moscow: Science, 535 p. (2004)

11. E.N. Lvov, Statistical methods for deducing empirical formulas: A manual for VTUZs. - 2 nd ed., Pererab. and additional. - Moscow: Higher Education, 239 p. (1988)

12. A.V. Lazarenko, A.N. Moiseev, O.B. Rogova, A.A. Solntsev, Modeling of the transportation schematics supply of spare parts and components in the dealership network. Automation and control of technical systems. No. 4.2. P. 8-14. (2013)

13. A.B. Nikolaev, Yu.S. Sapego, A.N. Jakubovich, L.I. Berner \& A.M. Ivakhnenko. Simulation of Automatic Incidents Detection Algorithm on the Transport Network. International Journal of Environmental and Science Education (IJESE). Volume 11 Issue 16. pp. 9060-9078. Article Number: ijese.2016.663. Published Online: October 23, 2016. e-ISSN: 1306-3065. Publisher: LOOK Academic Publishers Journal Abbreviation: Int J Env Sci Ed (Web of Science) (2016)

14. A.B. Nikolaev, Y.S. Sapego, A.M. Ivakhnenko, T.E. Mel'nikova, V.Y. Stroganov, Analysis of the incident detection technologies and algorithms in intelligent transport systems. International Journal of Applied Engineering Research ISSN 0973-4562 Volume 12, Number 15 (2017) pp. 4765-4774. (2017)

15. N. Verevkin, E. Lavrentyev, I. Chernyaev, D. Gurin, Method of Providing Safe Technical Condition of Vehicles by Technological Design of Enterprises. Transportation Research Procedia Volume 20, Pages 665-670 (2017)

16. A. Kapustin, A. Terentiev, Rational Lifetime of a Vehicle in Terms of Ensuring Security of Its Design. Transportation Research Procedia Volume 20, Pages 254-260 (2017)

17. S. Vorobyov, I. Chernyaev, V. Nazarkin, K. Filippov, Model of Operation of Motor Vehicles Based on Monitoring of their Performance Characteristics. Transportation Research Procedia Volume 20, Pages 695-701 (2017)

18. S. Zhankaziev, Current Trends of Road-traffic Infrastructure Development. Transportation Research Procedia Volume 20, Pages 731-739 (2017) 